\title{
O Ceticismo Probabilístico e a Psicologia
}

\author{
Arno Engelmann \\ Universidade de São Paulo
}

\begin{abstract}
RESUMO - O artigo apresenta uma pesquisa psicológica na qual sujeitos humanos se manifestam por meio de relatos verbais a questões chamadas de filosóficas. No caso presente, as perguntas referem-se a alguns fundamentos da doutrina cética probabilista. Os sujeitos foram 46 pessoas que assistiram à minha conferência, durante a $31^{\mathrm{a}}$ Reunião da Sociedade de Psicologia, no Rio de Janeiro em 2001. O método consistia em duas perguntas escritas do tipo verdadeiro-falso. Os resultados confirmaram minhas hipóteses que não existe semelhança entre a consciência imediata do sujeito e as consciências de outras pessoas e que, além disso, cada consciência imediata é diferente da própria consciência de um minuto atrás. Mais tarde, interessados no assunto poderão realizar pesquisas mais bem elaboradas. Em segundo lugar, o artigo apresenta as hipóteses básicas que fundamentam o ceticismo probabilístico, bem mais discutidas do que em outros escritos a respeito. Chamo de hipóteses básicas as hipóteses iniciais nas quais se baseiam as inúmeras hipóteses científicas empíricas posteriores.
\end{abstract}

Palavras-chave: Psicologia; Filosofia; ceticismo; ciência empírica; hipótese.

\section{Probabilistic Skepticism and Psychology}

\begin{abstract}
The main criteria that characterize researches in which philosophical principles are manifested through human psychological verbal reports are a new realm of knowledge. An example could be the present case, where some results from probabilistic skeptic doctrine were referred as positive or negative by human subjects. Forty-six people that listened to my 2001 Rio de Janeiro lecture were the psychological subjects. Two true-false items to philosophical questions were the only methodological process. The results about (1) the non existence of similarity between each subject's immediate consciousness and the consciousness of others and (2) the difference between the subject's immediate consciousness and his one minute consciousness prior to immediate consciousness confirmed my hypotheses. Further researches about similar but better done philosophical questions could be later undertaken. In the second place, I discuss better the fundamental probabilistic skepticism basic hypotheses than I did in other writings. I call basic hypotheses the initial hypotheses that mark a foundation for numerous later empirical scientific hypotheses.
\end{abstract}

Key words: Psychology; Philosophy, skepticism; empirical science; hypothesis.

O título do meu artigo é "O ceticismo probabilístico e a psicologia". Psicologia é um termo bem conhecido para prováveis leitores. Entretanto, ceticismo probabilístico pode parecer estranho. É uma doutrina filosófica. De acordo com o ceticismo, o ser humano nunca pode chegar a verdades absolutas. De acordo com o ceticismo probabilístico, o ser humano nunca pode chegar a possuir um conhecimento realmente verdadeiro, ainda que seja capaz de se aproximar desse ponto na medida em que aumenta a probabilidade subjetiva desse conhecimento. Um outro nome é ceticismo mitigado. Por exemplo, sabe-se de inúmeras, mas mesmo inúmeras, observações em que a Terra apresenta uma forma mais ou menos esférica. Porém, por maior que sejam estas observações, há sempre a eventualidade de se encontrar a negação dessa verdade. Qualquer ser humano que olha para fora vê uma parte desse mundo, não como esférico, mas como plano. É necessário que se veja o desaparecimento de navios que se afastam no mar. Nesse caso, o início é pelo casco e o término pela parte superior. Aí teremos uma prova simples que a superfície da Terra parece ser esférica e não plana. Sabe-se, hoje em dia, que a Terra pode ser fotografada de longe a partir de um satélite artificial e parecer uma bola

1 Endereço: Rua da Consolação, 3617, Apt. 42. São Paulo, SP, CEP 01416-001. azul. Entretanto, houve um pensador relativamente recente na Alemanha nazista que acreditava que, apesar da superfície da Terra parecer convexa, seria na realidade uma superfície côncava. A Terra seria o envoltório interno de uma bola que contenha dentro dela tudo o que normalmente achamos fora da Terra: o Universo.

O início de qualquer tipo de ceticismo é sempre, do meu ponto de vista, a experiência imediata de Tolman (1935/1951) ou, utilizando outras palavras, o "isto" ou o meu-mundo ou a consciência-imediata em meus textos (Engelmann, 1997a, 2001). "Experiência" no texto de Tolman e de muitos psicólogos da época era sinônimo de "consciência". Entretanto, pelo uso homônimo da palavra "experiência" com sentido de observação controlada, o primeiro sentido foi abandonado, principalmente pelos psicólogos.

"Isto" é o nome que usei para denominar aquilo que é, aquilo que imediatamente é. "Isto" é o conhecimento absolutamente verdadeiro. Portanto, seria uma parte realista e não cética do meu pensamento. Entretanto, a duração do "isto" é mínima e além disso não se produziria em outras pessoas. O resto todo é realmente cético. "Fora" é esse resto que não cabe na definição de "isto" (Engelmann, 1997a).

Por exemplo, você leitor pode perceber no presente uma sala em que há uma série de objetos, você pode sentir ao mesmo tempo uma emoção, você pode pensar no que seria o "ceticismo probabilístico", você pode se lembrar agora 
como acordou hoje de manhã, você pode pensar no caminho que você fará quando acabar de ler o presente texto. Tudo isso é parte do seu "isto". Como parte do "fora", você não conhece absolutamente nada. Entretanto, como posso dizer que você não conhece absolutamente nada, se você pode pensar, pelo menos, em ocorrências que se dão fora de você? Se você pensar em alguma coisa fora de você, essa alguma coisa, essa lembrança se torna parte do seu "isto". Somente são partes do "fora" ocorrências com a quais vocês não têm qualquer modo de relação no momento presente. E, se você não têm qualquer modo de relação com as pessoas, animais, plantas ou objetos, então não conhece disso absolutamente nada. É evidente que se você se lembra agora de algum fato que você antes não lembrava, esta lembrança atual sua não vai fazer parte do "fora" mas do "isto".

Como o "fora" ocupa uma parte enorme diante da miniminúscula parte que corresponde ao "isto", achei mais tarde chamar o "fora" de resto-do-mundo e, por conseqüência, o "isto" de meu-mundo (Engelmann, 2001). Entretanto, o "isto", o primeiro nome, é mais correto. Meu-mundo seria um termo que qualifica o mundo como meu. E qualificá-lo de meu já pode supor um mundo-não-meu. Realmente, a palavra "isto" não supõe essa alternativa.

Ainda, de maneira semelhante a Tolman, dividi a consciência em duas, e, de modo diferente de Tolman, chamei ambas de consciência: a consciência-imediata, idêntica ao "isto" ou meu-mundo, e a consciência-mediata, que é conhecida para um observador através da mediação de outras partes. Essa mediação pode ser a própria memória - consciênciamediata-do-observador — ou em primeiro lugar a parte do observador, a seguir o ar circundante e finalmente a parte do animal humano ou não-humano que apresenta consciência - consciência-mediata-de-outros. Para Tolman o que chamei de consciência-imediata ele denominou de "impressão crua" em 1932 e de "experiência imediata" em 1935; para Tolman o que chamei de consciência-mediata ele denominou simplesmente de "consciência" (Engelmann, 1997a, 2001; Tolman, 1932/1960, 1935/1951).

A consciência-imediata (1) é uma consciência individual, não coletiva, e (2) apresenta uma duração momentânea. É assunto de filosofia e não de psicologia, uma das ciências empíricas.

Qual a diferença entre as ciências empíricas e a filosofia? É difícil apresentar uma explicação adequada para todas as partes constituintes. Entretanto, há um ponto com relação ao qual as duas divergem.

Basicamente, numa ciência empírica observa-se detidamente um acontecimento e teoriza-se sobre o observado. A observação nunca é única. Ao contrário, há uma série de observações, cada qual ocorrendo em inúmeras consciência-s-imediata-s. Essas inúmeras consciências-s-imediata-s evidentemente pertencem a um observador; mas, além disso e é muito importante, são também de outros observadores. A ciência empírica é efetuada por diversos observadores, a não ser situações particulares que podem reduzir o número de observadores a somente um. Se for permitido pelo tipo de ciência, pode-se utilizar esquemas experimentais. Nesse tipo de esquema há um controle grande das variáveis independentes que podem agir sobre a observação. As conclusões são o resultado do intercâmbio entre teorização e observação.
O filósofo, ainda que comece a produzir após passar por um bom conhecimento de sua área, não necessita realizar as observações comuns nas ciências empíricas. A obra de um filósofo é obra completamente sua. No entanto, há cientistas empíricos que fazem, de vez em quando, filosofia e há filósofos que fazem, de vez em quando, ciência empírica.

Há inúmeras questões que são apresentadas por filósofos. Essas questões são respondidas por outras pessoas que se interessam por filosofia. Creio, entretanto, que se houver um enquadramento psicológico adequado, essas perguntas serão respondidas não apenas por outras pessoas, mas por sujeitos. Sujeito é o nome que se dá ao organismo humano ou não-humano numa dada situação estimulatória e que, por consequiência, dá origem ao específico comportamento (Fraisse, 1963; Woodworth e Schlosberg, 1938/1954).

As perguntas são de teor filosófico. Os sujeitos são seres humanos. Os observadores estão interessados em fatos que ocorrem nas consciências-mediatas-de-outros dentro das pessoas. Os comportamentos através dos quais se vai inferir o que ocorreu nesses sujeitos utilizam uma espécie de indicador de consciência chamado de relato, isto é, aquele que apresenta uma estrutura semelhante àquilo que é relatado. Os relatos são verbais, isto é, aqueles que se valem de uma língua natural. A maneira de exprimi-los são relatos verbais gráficos, isto é, aqueles que utilizam a linguagem escrita (Engelmann, 1997b).

Como um exemplo de tal observação psicológica de natureza filosófica, mandei distribuir aos que assistiam à conferência na qual baseei o presente artigo duas perguntas. Evidentemente, não controlei a provável influência do conhecimento filosófico ou pelo menos do grau em que tiveram tais tipos de pensamentos gerais. Não controlei a sala em que as pessoas responderam. Não controlei o tempo dado para a resposta. Portanto, não posso achar os resultados completamente confiáveis. Com bom controle das perguntas e da situação, espero futuramente um meio para crer em muitas afirmações filosóficas que, no caso, seriam captadas por meios psicológicos.

Apesar de todas as falhas, posso apresentar os resultados obtidos. Duas perguntas foram realizadas acerca da consciência-imediata: uma acerca da identidade da consciênciaimediata e de algumas consciências-mediatas-de-outros; e a segunda acerca da identidade da consciência-imediata e da consciência-mediata-do-observador de um minuto atrás. As respostas possíveis eram "Sim" ou "Não". Sessenta e cinco sujeitos responderam. Quarenta e seis foram de sexo feminino, 17 do masculino e 2 deixaram o espaço em branco para a identificação do sexo e da idade. A idade média dos 63 foi 30,59 anos, variando entre 18 e 65 anos. Na primeira pergunta, 86,2\% responderam "Não", 19,8\% responderam "Sim"; na segunda pergunta, 96,9\% responderam "Não", $3,1 \%$ responderam "Sim". Submetendo os dois resultados ao teste não-paramétrico da binomial, as hipóteses aceitas são altamente significativas em ambos os casos. Veja o Apêndice sobre a pesquisa.

Manifestei publicamente no início do artigo que sou cético probabilístico. Há duas doutrinas filosóficas para explicar a captação da verdade do que se observa no exterior: o dogmatismo, que afirma que há pelo menos uma verdade fora do eu momentâneo, e o ceticismo, que afirma que não há nenhuma 
verdade absolutamente certa fora do eu momentâneo. Uma forma de dogmatismo é o realismo, tal como foi exposto por filósofos dos últimos dois séculos: a existência do Universo é verdadeira. O ceticismo pode ser principalmente pirrônico ou probabilístico. De acordo com o ceticismo pirrônico, há suspensão de julgamento, qualquer que seja a ocorrência. De acordo com o ceticismo probabilístico ou mitigado, além da suspensão de julgamento, haverá ocorrências cuja probabilidade é maior e ocorrências cuja probabilidade é menor, baseado na freqüência anterior das ocorrências ou na crença que se ouvem ou se lêem a respeito.

É interessante que meu ceticismo seja visto por Popkin (1967) como extremo, na medida em que se origina sempre da que chamo de consciência-imediata, e como mitigado, no uso de uma versão de probabilismo. Probabilismo se baseia na obra de Cournot. Este autor chamava a probabilidade em questão de subjetiva ou filosófica. No momento presente, a probabilidade subjetiva pode-se mostrar com uma convicção inquebrantável. Entretanto, se o critério para aceitá-la se altera, por conseguinte muda a probabilidade subjetiva (Cournot, 1851/1975).

Para mim a probabilidade subjetiva pode adquirir qualquer valor, a não ser o valor máximo ou o valor nulo. Os valores apresentam-se numa escala de mensuração ordinal. Uma probabilidade pode ser maior ou menor do que outras. Se houver várias probabilidades de objetos, então as probabilidades podem ser postas numa escala ordinal. Entretanto, além da ordem das probabilidades, a distância relativa entre elas não existe. Não é uma escala racional, isto é, a normal utilizada em aritmética, nem uma escala de intervalos, como a da temperatura centesimal. Exemplos de escala ordinal seria o sistema de graus do sistema militar, isto é, no exército brasileiro cabo $<$ sargento $<$ tenente $<$ major $<$ coronel $<$ general; a dureza de minerais pela escala de Mohs na qual um mineral superior risca todos os inferiores; a agradabilidade de odores; etc. (Engelmann, 1997a; Stevens, 1951).

Hipótese para Lalande, no seu conhecido "Vocabulário Técnico e Crítico da Filosofia", é uma "proposição admitida, independentemente da questão de saber se ela é verdadeira ou falsa, ..." (Lalande, 1926/1993, p. 466). Por exemplo, uma ocorrência comum é que uma moeda largada no ar cai no chão. A hipótese mais freqüente, hoje em dia, é da gravitação universal. Entre dois corpos existiria sempre uma atração tal que a força seria dada pela massa de um vezes a massa do outro dividida pelo quadrado da distância entre eles e multiplicada pela aceleração da gravidade. Descontando o ar entre eles e o fato da massa da Terra ser imensamente superior à massa da moeda, a aceleração será realmente função da gravidade. Antes dessa explicação, era comum aceitar-se a hipótese aristotélica. Haveria qualidades diferentes de matéria: os corpos pesados caiam para a Terra e para o centro do Universo; os corpos leves subiam para a circunferência do Universo. O Universo para Aristóteles era esférico; a Terra era o centro; as estrelas, a parte superficial. A moeda seria um corpo pesado e por isso cai. Os acontecimentos do Universo são explicados através de hipóteses e cada hipótese é uma explicação à qual um indivíduo dá maior ou menor probabilidade de aceitação.

O início da explicação cética probabilista é uma verdade. Entretanto, essa verdade, como já dissemos, é individual e momentânea. Muda de momento para momento. Como explicar o Universo das ciências empíricas, baseando-se no individual momentâneo?

Baseei-me em certas hipóteses básicas que, do meu ponto de vista, explicariam a passagem do individual momentâneo ao coletivo geral, característica da ciência empírica. Seriam anteriores a hipóteses mais específicas. Presentemente, acho que o número delas é oito. Pretendo apresentá-las em ordem de prioridade.

Antes de continuar, quero definir mais alguns termos que serão utilizados. Fenômeno é qualquer ocorrência no "isto" ou meu-mundo ou consciência-imediata. Acontecimento é qualquer ocorrência no "fora" ou resto-do-mundo. Ocorrência baseia-se ou no fenômeno ou no acontecimento.

O Universo que a pessoa conhece como verdade absoluta resulta numa espécie de solipsismo. Mas não é o solipsismo comum; é o que Russell chamou de solipsismo-do-momento: o "isto" no momento que existe. Sem a aceitação das hipóteses básicas, é um solipsismo metafísico, isto é, a única realidade. $\mathrm{O}$ solipsismo-no-momento seria melhor definido simplesmente como "o momento que existe", nada mais. Russell crê que psicologicamente é impossível crer no solipsismo-do-momento. Acho que Russell apresenta enorme razão nesta impossibilidade de crer. Entretanto, e isso de acordo com o mesmo Russell, é impossível negar por meio dedutivo a crença na realidade do solipsismo-do-momento (Rollins, 1967; Russell, 1948).

Husserl (1950), ainda que fosse um opositor de qualquer ceticismo, na épochê ou redução fenomenológica, parte da desconexão do mundo circundante natural para chegar a uma realidade "entre parênteses". Husserl acha que a redução é absolutamente necessária no caminho da chegada às essências (Lyotard, 1954/1967). Sem falar nas essências husserlianas, creio que - ao contrário do caminho de Husserl partindo do mundo natural para chegar ao mundo reduzido - esse mesmo caminho deve ser trilhado, mas em sentido contrário. Deve-se partir do "isto" e chegar, após a aceitação das hipóteses básicas, ao mundo natural.

Porque não verificar a origem das percepções e dos pensamentos no passado dos seres humanos e, ao contrário, achar que o presente da consciência-imediata será o início? No presente, é frequiente pensar na origem daquilo que não ocorre agora. Porém sempre que eu penso na origem do pensamento, essa origem é uma questão que faço agora, não é uma questão que se origina no passado. E sendo agora, esse agora é o início daquele pensamento.

A nossa ciência empírica apoia-se no tempo. E nossa compreensão do que ocorre apoia-se exclusivamente no tempo. No entanto, a maneira pela qual se utiliza essa compreensão baseia-se numa capacidade de muitos animais na qual, pelo que sabemos dos seres humanos, ocorre apenas presentemente. Portanto, cada vez que ocorre é a consciência momentânea, é a consciência-imediata ou "isto".

Voltemos agora às hipóteses básicas (veja Figura 1).

A primeira hipótese básica é a da duração ou solipsista. Afirma que além da duração curtíssima do "isto", existem "fora-s" que anteriormente foram "isto-s". Uma outra maneira de afirmar este fato é dizer que a primeira hipótese é solipsista.

A consciência pessoal parece contínua. É a terceira característica da corrente de consciência de William James. 


\begin{tabular}{ll}
\hline \multicolumn{1}{c}{ Hipóteses de Fundamento Ontológico } \\
\hline 1. Hipóteses da duração ou solipsista \\
2. Hipótese dos "foras-não-partes-do-eu" \\
3. Hipótese da constituição comum \\
4. Hipótese da semelhança entre o "fora-não-parte-do-eu", de um \\
lado, e os "pseudo-foras-não-partes-dos-pseudo-eus", de outro \\
\hline \multicolumn{1}{c}{ Hipóteses de Fundamento Científico Empírico } \\
\hline 5. Hipótese da compreensão de Kant e Einstein \\
6. Hipótese da divisão dos acontecimentos em fatuais e teóricos \\
7. Hipótese da divisão dos acontecimentos fatuais em superficiais e \\
profundos \\
8. Hipótese da divisão dos acontecimentos fatuais profundos em \\
dinâmicos e estáticos
\end{tabular}

Figura 1. Hipóteses básicas.

Parece que ela não é nunca quebrada para a pessoa que a tem, a não ser por interrupções durante o sono. Entretanto, mesmo o sono se não estiver sinalizado para a pessoa que dormiu, passará sem a pessoa saber que houve uma interrupção. James imaginou que o presente é como a luz de um pirilampo. $\mathrm{O}$ presente está em contínua mudança. A luz do pirilampo ocupa um espaço, mas esse espaço muda continuamente. James, como todos nós, fala do tempo imaginando um espaço para explicá-lo. É a maneira com que representamos o tempo. Mas será a maneira correta? Não sabemos. A única coisa que sabemos é que uma parte de nossa consciência-imediata está se tornando continuamente um passado recente (James, 1890/1950; 1892/1961).

Se você está numa consciência-imediata - e evidentemente as pessoas conscientes estão sempre numa consciência-imediata —, quando será que a consciência-imediata começa e quando termina? As pessoas nunca sabem quando isso ocorre. Entretanto, quando uma ocorrência é passada há bastante tempo, posso saber disso. Se me lembro de uma ocorrência passada, tenho no momento uma lembrança do passado. E a lembrança não é uma ocorrência passada, é uma ocorrência presente. Pode não se assemelhar ao passado. Inclusive, pode não haver um passado no qual teria existido, ainda que atualmente seja uma lembrança (Loftus e Ketcham, 1994).

Sempre que ouço música, é apenas um trecho da peça. Entretanto, a estrutura da peça musical é maior do que o momento do "isto". Como isso ocorre? É uma questão difícil de responder. Sempre que se vai procurar saber o que se ouve, é um "isto" com a estrutura musical que se desenvolve. Como se dá? Não sei.

A segunda hipótese básica é a dos "foras-não-partesdo-eu”. Afirma que além dos "fora-s" que num momento anterior foram um "isto", existem também os "foras" que nunca foram um "isto". Se o "eu" for constituído pelo "isto" e pelos "foras" que foram anteriormente "isto", a segunda hipótese afirma a existência dos "foras" que nunca compuseram partes do "eu". Entretanto, não sei se neste mundo há pessoas ou se há seres vivos ou se há pelo menos apenas substâncias minerais. O solipsismo-do-momento e mesmo o simples solipsismo são sempre hipóteses, mas com uma probabilidade extremamente pequena.
A terceira hipótese básica é a da constituição comum. (a) Afirma que de forma semelhante a mim que tenho um "isto", há nos "foras" alguns que se expressam da mesma forma que o "isto". São os "pseudo-istos". (b) Além disso, afirma que cada "pseudo-isto" apresenta o seu "pseudo-fora". Este "pseudo-fora" seria igual ao "isto" mais o "fora" menos o "pseudo-isto" em questão. (c) Finalmente, a constituição seria comum entre o "eu" e os diferentes "pseudo-eus", sendo formado cada "pseudo-eu" por um "pseudo-isto" e seu característico "pseudo-fora".

A constituição comum lembra a intersubjetividade de Husserl (1954) e de Merleau-Ponty (1945). Entretanto, Husserl como Merleau-Ponty partem do realismo. A minha explicação, ainda que de certa forma mais complicada, é cética. Há pouco tempo, Nelson Coelho Jr. (2002) criticou o meu ceticismo, lembrando o percepto duplo de uma pessoa que ao tocar com a mão direita a sua mão esquerda, percebe de um lado o percepto de sua mão esquerda relativa à sua mão direita e de outro lado o percepto de sua mão direita relativa à sua mão esquerda, baseado isto em Husserl (1952) e, daí, em Merleau-Ponty (1960). Esses perceptos alternados duplos seriam fenômenos que destruiriam o ceticismo. Respondi que a totalidade do percepto, e não os dois perceptos cada um, pode estar errada. Posso sonhar que há dois perceptos, posso possuir a ilusão de que há dois perceptos. Apesar disso, a correspondência entre o fenômeno do "isto" e o acontecimento do "fora" pode não ocorrer. Até agora, todos os argumentos que li contra o ceticismo padecem do mesmo contra-senso (Engelmann, 2002a).

A quarta hipótese básica é a da semelhança entre o “fora-não-parte-do-eu”, de um lado, e os "pseudo-forasnão-partes-dos-pseudo-eus", de outro. Afirma que o "fora" externo de cada pessoa, seja eu mesmo ou sejam "eus" de outras pessoas, parece o mesmo. Porém a semelhança não é a mesma coisa que identidade. Há sempre a possibilidade de duas percepções do Universo não serem exatamente as mesmas. Apesar de tudo, a ciência empírica se vale dessa semelhança para prosseguir.

A quinta hipótese básica é a da compreensão de Kant e Einstein. Afirma que os acontecimentos do "fora" são ordenados de uma maneira compreensível para o observador. Sua origem próxima é devida a Albert Einstein. É a compreensibilidade na produção de uma ordem geral. É a semelhança entre a ordem do Universo e a ordem que pode ser compreendida pela consciência-imediata. É uma série de relações gerais que podem ser conhecidas. "...o mundo de nossas experiências é compreensível. O fato de ser compreensível", de outro lado, "é um milagre" ". Como Einstein o reconheceu, ao falar desse fato foi influenciado por Kant (Einstein, 1936/1956).

Essa ordem compreensível pode ser elementarista ou pode ser em parte elementarista e em parte gestaltista ou pode ser totalmente gestaltista. A ordem elementarista julga que o Universo é constituído de partículas elementares independentes que se unem. A ordem gestaltista julga que os todos ou gestalten se subdividem em partes, mas que serão partes sempre da gestalt originadora (Engelmann, 2002b). Os três tipos de ordens contam com inúmeros investigadores.

2 Minha tradução de Einstein (1956, p. 61) 
As diferenças são tratadas depois de aceitas as oito hipóteses básicas. O importante é que a ordem - elementarista, gestaltista ou mista - é compreensível.

A sexta hipótese básica é a da divisão dos acontecimentos em fatuais e teóricos. Afirma que há acontecimentos fatuais ou fatos, inferidos a partir de fenômenos passivos proeminentes e fenômenos ativos não-proeminentes, e acontecimentos teóricos ou teorias, inferidos a partir de fenômenos ativos proeminentes e fenômenos passivos não-proeminentes.

Podem-se citar como exemplos de acontecimentos fatuais, a "janela do meu quarto de dormir", um "siri", um "átomo de carbono", "D. Pedro II"3. Exemplos de acontecimentos teóricos são "dois grupos de ratos que foram reforçados na mesma quantidade de reforço, porém de acordo com dois padrões diferentes: padrão de $100 \%$ e padrão de $50 \%$ " ou a "lei de potência de S. S. Stevens" ou a "teoria da relatividade geral de Einstein".

A sétima hipótese básica é a da divisão dos acontecimentos fatuais em superficiais e profundos. Os acontecimentos fatuais se dividem em dois: aqueles que o observador, feita a primeira inferência, percebe diretamente acontecimentos que chamo de superficiais; e aqueles na qual o observador realiza uma segunda inferência tendo como base acontecimentos superficiais, e que chamo de profundos.

Os observadores sempre realizam observações científicas tendo em vista acontecimentos profundos. Entretanto, os perceptíveis são sempre acontecimentos superficiais. A busca de acontecimentos profundos inclusive pode abranger acontecimentos que parecem à primeira vista superficiais. Por exemplo, um zoólogo está interessado na cor das penas de uma espécie de pato. A observação de um único acontecimento superficial não é de maneira nenhuma científico. Será necessário repetir a observação um número de vezes tal que o resultado possa ser considerado adequado. Os acontecimentos superficiais das penas coloridas quase sempre se dão dentro de um padrão mais ou menos exato diferente dos acontecimentos superficiais. A conseqüência é o acontecimento profundo da cor das penas.

A oitava e última hipótese básica é a da divisão dos acontecimentos fatuais profundos em dinâmicos e estáticos. Afirma que os acontecimentos fatuais profundos podem ser divididos em dinâmicos fluidos e estáticos duráveis.

Realmente, todos os acontecimentos do Universo parecem ser sempre, em última análise, dinâmicos. Entretanto, há acontecimentos tão lentamente modificados que é melhor dar-lhe o nome de estáticos. Inclusive, a dinâmica é tão lenta que a passagem de seres vivos ocupa apenas uma parte pequena de sua existência. O Universo apresenta uma boa parte de acontecimentos estáticos.

Evidentemente, na medida que as oito afirmações são hipotéticas, qualquer uma delas apresenta pelo menos uma hipótese de teor contrário à anterior. Assim, além da hipótese básica da duração, há a hipótese básica do solipsismo-domomento. Afirma a existência apenas do "isto". Além da hipótese básica da semelhança entre o "fora-não-parte-doeu" e os "pseudo-foras-não-partes-dos-pseudo-eus", há duas outras hipóteses básicas: a da identidade e, de outro lado, a

3 Segundo imperador do Brasil. da diferença. Além da hipótese básica da divisão dos acontecimentos fatuais em superficiais e profundos, há a hipótese básica da ausência da divisão dos acontecimentos baseados em superficialidade e profundeza.

As hipóteses básicas são ontológicas, as quatro primeiras, e científicas empíricas, as quatro restantes. As hipóteses básicas ontológicas procuram chegar ao início do conhecimento. Começam com o "isto" e terminam com um conjunto de seres humanos a perceberem um ambiente. As hipóteses básicas científicas apresentam as exigências de uma ciência empírica.

Porquê denominei as quatro primeiras hipóteses básicas de ontológicas? Introduzi no âmbito científico, mais exatamente em seres humanos, conceitos filosóficos. E por quê? Por terem esses seres humanos a capacidade de conscientemente realizarem perguntas em relação ao Universo do qual são partes. Essas perguntas feitas de maneira cuidadosa podem dar origem, em último caso, a pesquisas científicas. Mas cada uma dessas perguntas é feita por um ser humano. Esse ser humano precisa fazer perguntas que traduzem a sua relação filosófica diante do Universo. Essa relação chamei de ontológica. Ontologia é uma maneira de conhecer algo sobre as coisas em si. A minha ontologia é, em primeiro lugar, cética e, em segundo lugar, probabilista. As perguntas são sobre o Universo e, dentro do Universo, também sobre seres humanos.

Não sei em que instante a aceitação de hipóteses básicas dão origem ao realismo não ingênuo. Mas é importante dizer que o realismo se torna válido. Mas é válido apenas como hipótese, ainda que a hipótese será altissimamente provável

Na minha concepção de ciência, as oito hipóteses básicas são absolutamente necessárias. Se aceitas, um número enorme de outras hipóteses constrói a ciência natural. Há hipóteses sobre a realidade de acontecimentos, como "um lápis que vejo na minha mesa", até hipóteses amplíssimas, como a "teoria da evolução de Darwin". Há hipóteses bem fortes, como "a Terra girar em torno do Sól", até hipóteses bem fracas, como a "teoria da transmigração das almas".

Aceitando-se a teoria geral de sistemas, nos seres minerais e nos seres vivos há níveis. No caso dos animais um dos níveis corresponde ao animal como um todo. De acordo comigo, o nome pode ser ou de organismo ou de mente. Ambas as palavras se referem ao mesmo acontecimento (Farthing, 1992; Miller, 1978). Entretanto, o nome de mente é seu uso presente e não a utilidade tradicional em que foi sinônimo de consciência ou, de emprego mais antigo ainda, de alma. Os organismos de muitos animais apresentam uma parte com relação à qual é possível entreter a hipótese do conhecimento. De acordo com essa hipótese, existe algo que, em geral, corresponde a uma parte do próprio organismo e parte do ambiente.

A minha consciência-imediata é momentânea. Mas quanto tempo duraria esse momento? De acordo com a doutrina do ceticismo, aceitando apenas o "isto" ou a consciênciaimediata, não se pode medir o tempo. O tempo exige pelo menos a comparação entre a consciência-imediata e uma série de durações conhecidas fora dela. Isso é impossível para a consciência-imediata, mesmo se nela houver o percepto de um relógio andando de acordo com o pretenso "tempo objetivo". O relógio, sendo parte da consciência-imediata, não apresentaria por si só a objetividade do tempo, já que esta 
objetividade requer pelo menos ser percebida por diversas consciências-mediatas-de-outros. E a existência de diversas consciências-mediatas-de-outros solicita a não existência apenas de uma consciência-imediata. Entretanto, é possível captar a duração do tempo presente de outras pessoas humanas. Esse tempo presente varia ao redor de dois e meio e três segundos e recebe o nome de presente percebido ou agora (Fraisse, 1957/1967; Pöppel, 1985/1988).

Como conceber um tempo que duraria em média a consciência-mediata-de-outros humana - 3 segundos - se a percepção de acontecimentos é muito maior? Um discurso de um orador é em geral muito maior que 3 segundos; uma música é muito maior que 3 segundos; as pessoas podem andar por um tempo bem maior que 3 segundos. Qual a vantagem para os psicólogos reduzirem o agora a uma duração tão reduzida?

Para mim, como exemplo bem significativo, o agora não abarca a maioria das percepções. Percebo as gestalten no resto-do-mundo e grande parte das gestalten seriam bem maiores do que 3 segundos. Entretanto, a única ocorrência realmente verdadeira é aquela que dura mais ou menos 3 segundos. Portanto, captando essa consciência-imediata individual e momentânea, esse fator filosófico, construo com os acontecimentos na minha consciência-mediata-do-observador percepções que seriam bem maiores do que a duração da consciência-imediata.

Apesar da enorme semelhança entre a concepção do filósofo João Paulo Monteiro e a minha, há, de acordo com ele, "argumentos filosóficos capazes de questionar a diferença forte estabelecida ... entre a inferencialidade do Resto-doMundo e a 'datidade' ('givenness' seria menos ruim) do Meu-Mundo" (J. P. Monteiro, comunicação pessoal por e-mail, 23-9-2001).

A existência de duas substâncias no sentido cartesiano ou de dois Mundos no sentido de Popper e Eccles, isto é, duas coisas tais que existam de tal maneira que elas precisam apenas de si mesmo para existir, me perseguiam desde que escrevi "A possibilidade do estudo científico da consciência" em 1991 (Descartes, 1641-1642/1647/1967; Engelmann, 1991; Popper e Eccles, 1977). Acho que sou radicalmente monista, isto é, que o Universo que existe é apenas um. Entretanto, escrevi no texto há onze anos que há uma tremenda diferença entre "isto" ou consciência-imediata e "fora". O "isto" (1) é real, (2) é atemporal e (3) é livre. Pelo contrário, obedecendo à mesma numeração, o "fora" (1) é construído, (2) é temporal e (3) é, como um todo, determinado. O "isto" é a verdade; o "fora" é um nada. Em 1997 e em 2001 repeti essa posição. Como não falar, então, de duas substâncias ou dois Mundos independentes (Engelmann, 1997a; 2001)?

O meu Universo se restringiria ao "isto" ou meu-mundo ou consciência-imediata? E as inferências, se forem aceitas, se ordenariam numa outra substância cartesiana ou num outro Mundo popperiano-ecclesiano? Creio que as inferências aceitas constituiriam uma mesma substância ou um mesmo Mundo que o "isto". Se sou um cético probabilista, aquilo que estabeleci como as hipóteses básicas apresentariam probabilidades extremamente altas? E apresentando probabilidades extremamente altas, mais forte é a probabilidade de serem partes do único Universo. Ceticismo é a possibilidade de negar qualquer apresentação ao "isto". Mas a possibilidade de negar não deve ser confundida com simplesmente negar. É também, com enorme freqüência, aceitar.

Para mim, a consciência-imediata é o único fato absolutamente verdadeiro. $\mathrm{Na}$ medida em que se comprovam consciências-mediatas-de-outros, principalmente em questões científicas, a consciência-imediata acha em tal assunto probabilidades muito altas. Creio que achar a natureza dessa experiência simplesmente uma conjectura é negar o único fato que se apresenta absolutamente verdadeiro (Monteiro, 2001).

Futuramente espero que questões filosóficas difíceis, como os fundamentos do ceticismo probabilista, encontrem alguma base em experimentos psicológicos.

\section{Referências}

Coelho Jr., N.E. (2002). Consciência, intencionalidade e intercorporeidade. Paidéia, 12 (22), 97-101.

Cournot, A.-A. (1975). Essai sur les fondements de nos connaissances et sur les caractères de la critique philosophique. Paris: Hachette. (Trabalho original publicado em 1851)

Descartes, R. (1967). Les méditations, les objections et les réponses. Em F. Alquié (Org.), Descartes - Cuvres philosophiques. Tome II (Duque de Luynes, Trad. do latim; pp. 375-1073). Paris: Garnier. (Trabalho original traduzido publicado em 1647; trabalho original em latim de 1641-1642)

Einstein, A. (1956). Physics and reality. Em A. Einstein (Org.), Out of my later years (pp. 59-97). Secaucus, NJ: Citadel Press. (Trabalho original publicado em 1936)

Engelmann, A. (1991). A possibilidade do estudo científico da consciência. Tese de Livre-Docência. Departamento de Psicologia Experimental. Instituto de Psicologia. Universidade de São Paulo. São Paulo.

Engelmann, A. (1997a). Dois tipos de consciência: a busca da autenticidade. Psicologia USP, 8 (2), 25-67.

Engelmann, A. (1997b). Principais métodos de pesquisar a consciência-mediata-de-outros. Psicologia USP, 8 (2), 251-274.

Engelmann, A. (2001). O meu-mundo e o resto-do-mundo. Psicologia: Reflexão e Crítica, 14, 211-233.

Engelmann, A. (2002a). A teoria das duas consciências - Comentários. Paidéia, 12 (22), 107-109.

Engelmann, A. (2002b). A psicologia da Gestalt e a ciência empírica contemporânea. Psicologia: Teoria e Pesquisa, 18, 1-16.

Farthing, G.W. (1992). The psychology of consciousness. Englewood Cliffs, NJ: Prentice-Hall.

Fraisse, P. (1963). La méthode expérimentale. Em J. Piaget, P. Fraisse e M. Reuchlin (Orgs.), Traité de psychologie expérimentale. I. Histoire et méthode (pp. 71-120). Paris: P. U. F.

Fraisse, P. (1967). Psychologie du temps. Paris: P. U. F. (Trabalho original publicado em 1957)

Husserl, E. (1950). Ideen zu einer reinen Phänomenologie und phänomenologischen Philosophie. Erstes Buch. Allgemeine Einführung in die reine Phänomenologie. Haia: Martinus Nijhoff.

Husserl, E. (1952). Ideen zur einer reinen Phanomenologie und phänomenologischen Philosophie. Zweites Buch. Phänomenologische Untersuchungen zur Konstitution. Haia: Martinus Nijhoff. 
Husserl, E. (1954). Die Krisis der europäischen Wissenschaften und die transzendentale Phänomenologie. Haia: Martinus Nijhoff.

James, W. (1950). The principles of psychology. New York: Dover. (Trabalho original publicado em 1890)

James, W. (1961). Psychology. The briefer course. New York: Harper Torchbook. (Trabalho original publicado em 1892)

Lalande, A. (1993). Vocabulário técnico e crítico da filosofia (F. S.Correia, M.E.V.J. Aguiar, E. Torres e M. G. Souza, Trads.). São Paulo: Martins Fontes.

Loftus, E. \& Ketcham, K. (1994). The myth of repressed memory. New York: St. Martin's Griffin.

Lyotard, J.-L. (1967). A fenomenologia (M.A.S.L. de Barros, trad.). (Trabalho original publicado em 1954)

Merleau-Ponty, M. (1945). Phénoménologie de la perception. Paris: Gallimard.

Merleau-Ponty, M. (1960). Le philosophe et son ombre. Em M. Merleau-Ponty (Ed.), Signes (pp. 201-228). Paris: Gallimard. Miller, J.G. (1978). Living systems. New York: McGraw-Hill.

Monteiro, J. P. (2001). Racionalidade conjectural. Manuscrito ainda não publicado.

Popkin, R.H. (1957). Skepticism. Em P. Edwards (Org.), The encyclopadia of philosophy. Vol. 7 (pp. 449-461). New York: Macmillan \& Free Press.
Pöppel, E. (1988). Mindworks (T. Artin, Trad. do alemão). Boston: Harcourt Brace Jovanovich. (Trabalho original publicado em 1985)

Popper, K.R. \& Eccles, J. C. (1977). The self and its brain. London: Springer.

Rollins, C.D. (1967). Solipsism. Em E. Paul (Org.), The encyclopadia of philosophy. [Vol. 7] (pp. 487-491). New York: Macmillan $\&$ Free Press.

Russell, B. (1948). Human knowledge. London: Routledge.

Stevens, S.S. (1951). Mathematics, measurement, and psychophysics. Em S. S. Stevens (Org.), Handbook of experimental psychology (pp. 1-49). New York: John Wiley.

Tolman, E.C. (1951). Psychology versus immediate experience. Em E. C. Tolman (Org.), Behavior and psychological man (pp. 94 115). Berkeley, CA: University of California Press. (Trabalho original publicado em 1935)

Tolman, E.C. (1960). Purposive behavior in animals and men. New York: Appleton-Century-Crofts. (Trabalho original publicado em 1932)

Woodworth, R.S. \& Schlosberg, H. (1956). Experimental psychology. New York: Henry Holt. (Trabalho original publicado pelo primeiro autor em 1938) 
Questionário

\section{Apêndice}

(1) Você apresenta nesse preciso momento uma percepção da sala, dos outros participantes, da fala ou do ruído da fala de outras pessoas, dos pensamentos que você tem, de lembranças que você porventura tem, de imagens, de emoções, de sensações do corpo, em resumo, de sua consciência. O que você observa na sua consciência no presente momento é algo que outras pessoas conhecem também, isto é, que outras pessoas acham iguais, idênticos, como você?

Lembro que

diferentes são duas ocorrências que apresentam conteúdos diversos,

semelhantes são duas ocorrências que apresentam conteúdos parecidos, e

idênticos são duas ocorrências que apresentam conteúdos perfeitamente iguais.

Sim $\square$ Não

(2) Esse algo que você conhece atualmente é exatamente o mesmo ou idêntico ao que você conhecia há um minuto?

$\operatorname{Sim} \square$ Não

Nota: As respostas interessam ao conferencista. Pode entregá-lo no fim da conferência. Entretanto, se não quiser, pode deixar de entregar.

Idade: Sexo:

Numa sala grande de Psicologia da Universidade Estadual do Rio de Janeiro, durante a 31 a Reunião da Sociedade de Psicologia, 65 sujeitos responderam, no início da conferência sobre "O ceticismo mitigado e a psicologia" feita pelo autor do artigo em outubro de 2001, por um período não maior que 10 minutos.

Sessenta e três indivíduos referiram a sua idade. Quarenta e seis desses foram do sexo feminino, 17 do sexo masculino e 2 não responderam a essa pergunta. A idade média foi de 30,59 anos. A idade mínima foi de 18 anos e a máxima de 65 anos.

Os mesmos 63 responderam quanto a seu sexo: 46 eram mulheres e 17, homens. Na primeira pergunta das 46 mulheres, 6 responderam "Sim" e 40, "Não"; 17 homens responderam "Sim" em 2 casos, "Não" em 15 casos. Submetendo as respostas das mulheres e dos homens ao teste não paramétrico do qui quadrado de duas amostras independentes, a hipótese nula com 1 grau de liberdade foi aceita. A segunda pergunta foi efetuada no caso das 46 mulheres, que não responderam "Sim" em nenhum caso. Os 17 homens responderam "Sim" para 2 casos e "Não" para os 15 restantes. Submetendo o resultado ao mesmo qui quadrado, as duas amostras deram o mesmo resultado que para a primeira pergunta. Portanto, para cada pergunta as duas amostras anteriores podem ser juntadas, tem autorização para serem consideradas uma só. Esse junção das duas amostras numa só deve ser ainda aumentada com os dois indivíduos que não responderam quanto ao seu sexo.

A primeira pergunta foi respondida por 65 sujeitos, havendo 9 respostas "Sim" e 56 "Não". Submetido o resultado ao teste não paramétrico da binomial, com uma correção para a transformação em distribuição normal por ter mais do que 25 sujeitos, a hipótese nula foi rejeitada. A segunda pergunta, foi também respondida pelos mesmos 65 sujeitos, havendo 2 respostas "Sim" e 63 "Não". O resultado pelo teste da binomial foi o mesmo. A hipótese nula foi novamente rejeitada.

A conclusão de responder a essas duas perguntas foi exatamente no sentido por mim esperado. Não sei, todavia, se houve alguma imposição da singularidade do idêntico. E não sei se houve respostas dadas depois dos dez minutos iniciais. Não encontrei rabiscos nos questionários. 